\title{
Myoblast transplantation improves cardiac function after myocardial infarction through attenuating inflammatory responses
}

\author{
Bo Wang ${ }^{1, *}$, Likui Zhang ${ }^{2, *}$, Hao Cao ${ }^{2, *}$, Junqi Yang ${ }^{1}$, Manya Wu ${ }^{1}$, Yali Ma ${ }^{1}$, Huimin \\ Fan'2, Zhenzhen Zhan ${ }^{1}$ and Zhongmin Liu ${ }^{2}$ \\ ${ }^{1}$ Key Laboratory of Arrhythmias of the Ministry of Education of China and Institute of Heart Failure, Shanghai East Hospital, \\ Tongji University School of Medicine, Shanghai 200120, China \\ ${ }^{2}$ Department of Cardiac Surgery and Institute of Heart Failure, Shanghai East Hospital, Tongji University School of Medicine, \\ Shanghai 200120, China \\ *These authors contribute equally to this work
}

Correspondence to: Zhenzhen Zhan, email: zhanzz@tongji.edu.cn Zhongmin Liu, email: liu.zhongmin@tongji.edu.cn

Keywords: myoblasts, transplantation, myocardial infarction, cardiac function, inflammation

Received: March 10, 2017 Accepted: May 15, $2017 \quad$ Published: May 27, 2017

Copyright: Wang et al. This is an open-access article distributed under the terms of the Creative Commons Attribution License 3.0 (CC BY 3.0 ), which permits unrestricted use, distribution, and reproduction in any medium, provided the original author and source are credited.

\section{ABSTRACT}

Myocardial infarction (MI) is a highly prevalent cardiac emergency, which results in adverse cardiac remodeling and then exacerbates progressive heart failure. Inflammatory responses in cardiac tissue after MI is necessary for myocardium repair and wound healing. However, the excessive inflammation is also a key component of subsequent heart failure pathology. Myoblast transplantation after MI have been fulfilled attractive effects on cardiac repair, but the complications of transplantation and the underlying mechanisms have not been fully elucidated. Here, we found that human myoblast transplantation into minipig myocardium decreased the infiltration of inflammatory cells, the expression levels of many pro-inflammatory genes and the activation of inflammation-related signal pathways, while upregulated the expression levels of anti-inflammatory genes such as IL-10 in cardiac tissue of minipig post-MI, which was contributed to the improved cardiac function, the decreased infarct area and the attenuated myocardial fibrosis. Moreover, co-culture of human myoblasts inhibited the production of IL-1 $\beta$ and TNF- $a$ as well as activation of MAPK and NF-KB signaling pathway induced by damage-associated molecular patterns such as HMGB1 and HSP60 in human THP-1 cells, which was partially attributed to the up-regulated production of IL-10. Collectively, these results indicate that myoblast transplantation ameliorates heart injury and improves cardiac function post-MI through inhibiting the inflammatory response, which provides the novel mechanism for myoblast transplantation therapy of MI.

\section{INTRODUCTION}

Myocardial infarction (MI) mainly caused by coronary artery occlusion has higher morbidity and mortality, and pathological progress of which includes ischemia-reperfusion injury, wound healing responses and cardiac remodeling [1]. Reperfusion injury leads to necrosis of cardiac myocytes and release of endogenous damage-associated molecular patterns (DAMPs) which recruit inflammatory cells to the infarct area [1]. These inflammatory cells, such as neutrophils, monocytes and macrophages, can clear necrotic debris and also contribute to acute reperfusion injury by releasing excessive inflammatory cytokines, matrix metalloproteinases and reactive oxygen species, leading to the expansion of infarct area [2,3]. In addition, inflammatory cells play a crucial role in the chronic phase, months and even years after the ischemic event, when low-grade inflammation 
persists in heart and peripheral organs [4]. Therefore, tight control and timely repression of this inflammatory response has the potential to limit reperfusion injury and improve outcome in acute MI event and chronic ischemic heart failure [5].

Over the past decades, various therapeutic methods including coronary artery bypass grafting (CABG), percutaneous coronary intervention (PCI) and cell-based transplantation rapidly blossom in ischemic heart diseases. Although CABG and PCI can restore blood flow, they are proved defective in risk of anesthesia, operation attack and have the possibility of augmenting inflammation [6-8]. Transplantation of adult bone marrow-derived stem and progenitor cells into the infarct myocardium improves infarct healing and the recovery of cardiac function after MI in experimental studies and in patients [9]. The transplanted cells may have effects on anti-apoptosis, proangiogenesis and anti-inflammation in a paracrine fashion $[9,10]$. However, transplantation of stem and progenitor cells is limited because of their oncogenicity and fastidious culture condition [11].

Skeletal myoblasts (SkMs) are derived from satellite cells which locate between the sarcolemma and the basal lamina of myofibers. When muscle goes through overstretching, straining, trauma, myoblasts are activated to enter the cell cycle, proliferate and terminally differentiate into myofibers [12]. Based on these characteristics, myoblasts have been applied to cure muscular dystrophy and get desirable outcomes [13-15]. Compared with stem and progenitor cells, myoblasts embrace the advantages of facility of procurement, rapidity of expansion in vitro, resistance to ischemic conditions, no ethic restriction and low oncogenicity [12]. Thus, myoblast therapy for ischemia cardiovascular diseases is desired and carried out well on animal models in recent years [16-19]. Menasche et al. performed the first human transplantation of myoblasts in patients with heart failure [20,21], and additional clinical trials also have reported that myoblasts injected into infarct myocardium of ischemic cardiomyopathy attenuated left ventricular remodeling and resulted in a amelioration in left ventricular dysfunction [22, 23].

Although myoblast transplantation has affirmative therapeutic effects, the underlying mechanisms remain not fully clear. In this study, we found that the expression levels of pro-inflammatory cytokines and the activation of inflammation-related signal pathway in heart tissues were markedly decreased in minipigs with MI and then subjected to myoblast transplantation. In addition, co-culture of human THP-1 cells with myoblasts resulted in the decreased production of inflammatory cytokines and increased IL-10 production of in THP1 cells stimulated with recombinational HMGB1. Our results demonstrate that myoblast transplantation improves cardiac function through alleviating inflammatory responses post-MI.

\section{RESULTS}

\section{Grafted myoblasts survive and proliferate in heart tissues of minipigs after MI}

Male human myoblasts were injected into border region of infarct zone in heart of minipigs with MI model constructed through ligation of left circumflex (LCx) coronary artery. First, antibodies to human myosin heavy chain $(\mathrm{MyHC})$ and histocompatibility antigen class I (HLA-I) were used to stain grafted myoblasts in minipig heart undergoing transplantation. As shown in Figure 1A, double positive myoblasts which expressed MyHC and HLA-I indeed survived in heart tissue of minipig one week and one month after transplantation, and the double positive myoblasts had a clumped distribution in heart tissue one month after transplantation. Although the clumped myoblasts cannot be determined to be derived from one clone or just migrate to get together, it is sure that the grafted human myoblasts successfully survive and proliferate in minipig heart one month or even longer after transplantation. These results were further confirmed by detecting the mRNA expression of human Y chromosome which was significantly increased in minipig heart tissue along with the time post transplantation (Figure 1B).

\section{Myoblast transplantation ameliorates cardiac dysfunction post-MI}

Next, we observed the effect of grafted myoblasts on myocardial injury and fibrosis as well as cardiac function. One month after myoblast transplantation, hematoxylin \& eosin (HE) staining of heart tissue showed that cardiomyocytes located around the peri-infarct region in heart with myoblast transplantation, while there were only myofibroblasts and collagen deposition around the peri-infarct region in control treatment (NC) group without myoblast transplantation (Figure 2A). Infarct area size was also significantly decreased in heart tissue of minipig with myoblast transplantation post-MI (Figure 2B). Consistently, the mRNA expression levels of fibrosis-related genes including Acta2, Colla1 and Col3a1 in heart tissue were also markedly down-regulated in myoblast transplantation group compared with control treatment group (Figure 2C). Furthermore, left ventricular ejection fraction (EF) and fractional shortening (FS), the two main parameters which can effectively reflect the change of cardiac function, were markedly increased in myoblast transplantation group compared with control treatment group. However, left ventricular end-systolic internal diameter (LVIDs) and left ventricular end-systolic volume (LVESV) were significantly decreased in myoblast transplantation group. Left ventricular end-systolic posterior wall thickness (LVPWs) and left ventricular end-diastolic posterior wall thickness (LVPWd) were upregulated in myoblast transplantation group compared 
with control treatment group and MI group (Figure 2D and Table 1). These data indicate that myoblast transplantation can attenuate myocardial injury and fibrosis, increase wall thickening at the ischemic area of heart, which in turn augments left ventricular systolic function and substantially improves cardiac function post-MI.

\section{The differentially expressed inflammation- related genes in heart tissue with myoblast transplantation}

To explore the mechanism by which myoblast transplantation promoted cardiac function recover after MI, we performed microarray analysis to observe differentially expressed gene profiles in peri-ischemia tissue from myoblast transplantation group and control treatment group. Hierarchical cluster of all differentially expressed genes (DEGs) and inflammation-related genes between these two groups were shown in heat map (Figure 3A and Supplementary Figure 1). There were 1041 up-regulated genes and 966 down-regulated genes (fold change $\geq 2$ ) in peri-ischemia heart tissue of myoblast transplantation group compared with those in control treatment group (Supplementary Figure 1). Moreover, 45 of a set of 82 differentially expressed inflammationrelated genes were significantly down-regulated, including pro-inflammatory cytokines such as TNF- $\alpha$ and IL-1 $\beta$ in heart tissue of minipig with myoblast transplantation (Figure 3A and Table 2). Some important genes involved in inflammation-related signal pathway, such as TLR4 and MAPK8, were also down-regulated in heart tissue of myoblast transplantation group, while anti-inflammatory gene IL-10 was up-regulated in heart tissue of myoblast transplantation group (Figure 3A and Table 2). We then arranged DEGs enrichment analysis in the Gene Ontology (GO) categories and Kyoto Encyclopedia of Genes and
A
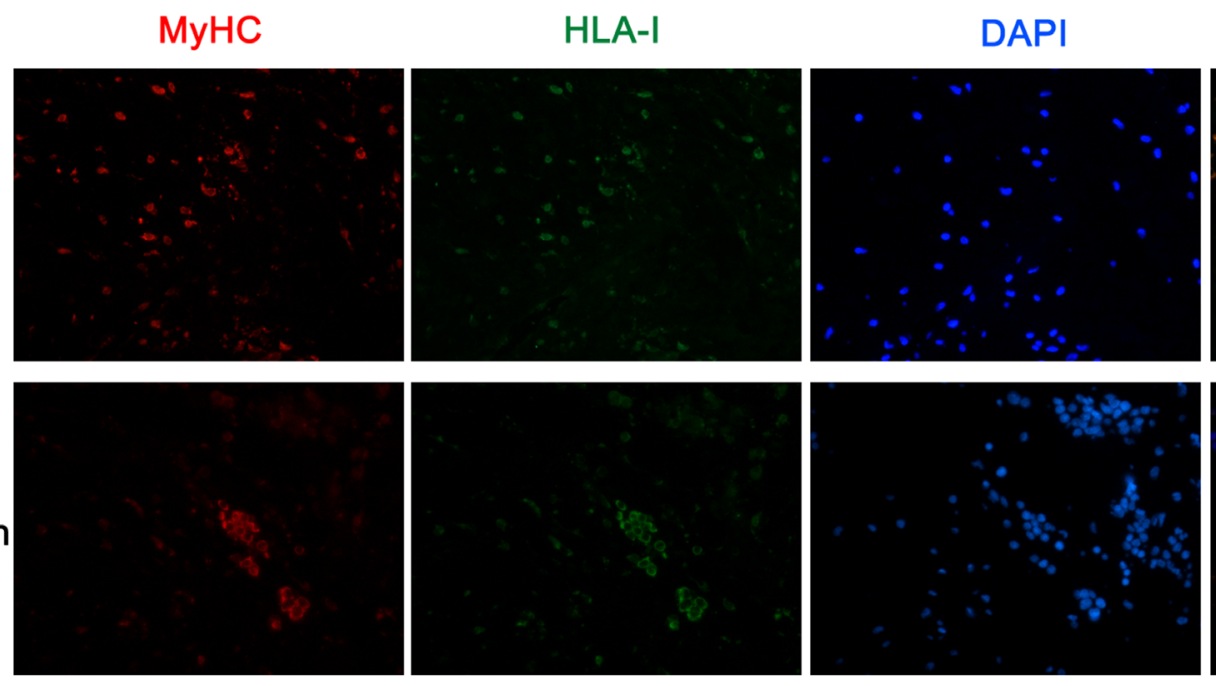

1 month

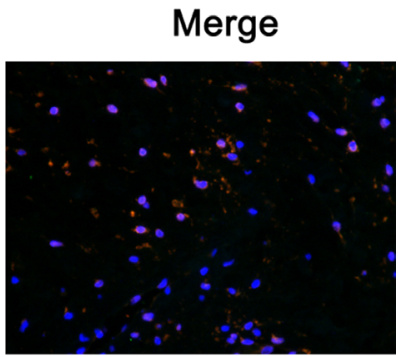

B

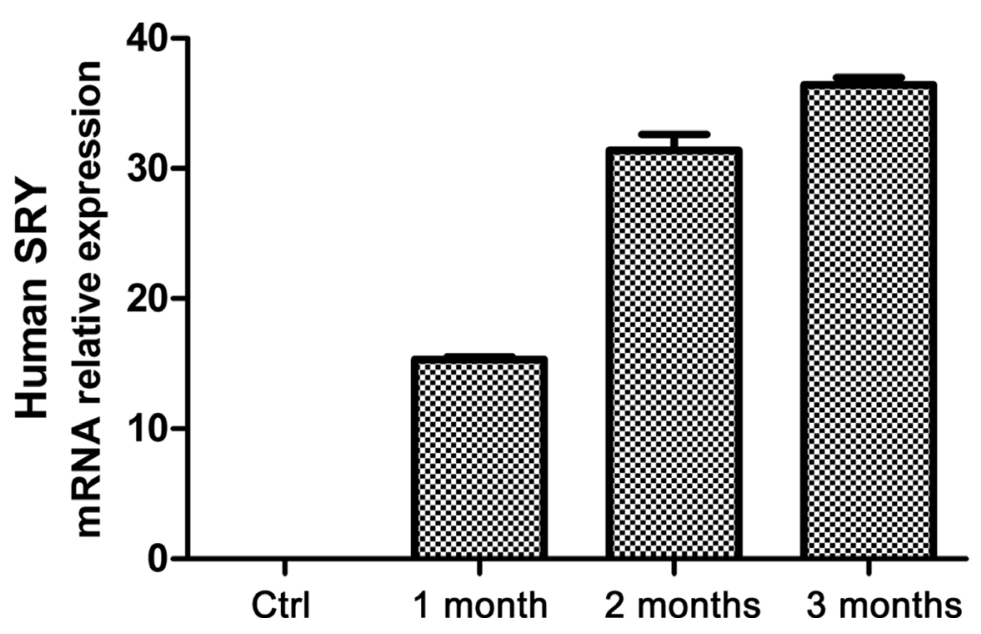

Figure 1: Grafted myoblasts survive and proliferate in heart tissue of minipig post-MI. (A) Immunofluorescence staining of MyHC (red) and HLA-I (green) in heart sections from minipigs with MI at 1 week and 1 month after myoblast transplantation. Original magnification, $\times 400$. (B) Q-PCR analysis of the expression of human Y chromosome in heart tissues of minipigs with MI followed by myoblast transplantation. Values are showed as the relative fold-change compared with control treatment groups $(n=6)$. Data are representative $(A)$, or mean \pm SEM (B) of 3 individual experiments. 
Table 1: Cardiac function assessment by 2-D echocardiography

\begin{tabular}{lcccc}
\hline \multirow{2}{*}{ 2-D Echo } & 0 week & \multicolumn{2}{c}{ 4 weeks } \\
\cline { 2 - 5 } & Sham $(\boldsymbol{n}=\mathbf{6})$ & MI $(\boldsymbol{n}=\mathbf{6})$ & NC $(\boldsymbol{n}=\mathbf{6})$ & Myoblasts $(\boldsymbol{n}=\mathbf{6})$ \\
\hline LVIDd $(\mathrm{mm})$ & $32.3 \pm 3.6$ & $37.2 \pm 4.2$ & $37.4 \pm 5.1$ & $36.3 \pm 3.8$ \\
LVIDs $(\mathrm{mm})$ & $21.3 \pm 2.5$ & $28.6 \pm 3.2$ & $27.1 \pm 2.3$ & $26.9 \pm 2.9 *$ \\
LVEDV (ml) & $43.6 \pm 4.7$ & $56.8 \pm 4.3$ & $57.7 \pm 4.9$ & $55.2 \pm 4.6$ \\
LVESV (ml) & $16.2 \pm 1.7$ & $31.2 \pm 2.4$ & $31.3 \pm 1.8$ & $26.3 \pm 2.1 *$ \\
FS (\%) & $34.8 \pm 3.6$ & $21.4 \pm 1.5$ & $22.7 \pm 1.2$ & $27.6 \pm 2.2 *$ \\
EF (\%) & $64.1 \pm 5.5$ & $44.8 \pm 4.2$ & $46.3 \pm 5.2$ & $52.1 \pm 4.7 *$ \\
LVPWs (mm) & $13.5 \pm 0.3$ & $6.5 \pm 0.4$ & $6.4 \pm 0.5$ & $10.4 \pm 0.4 *$ \\
LVPWd (mm) & $8.3 \pm 0.4$ & $5.1 \pm 0.3$ & $5.3 \pm 0.4$ & $6.6 \pm 0.2^{*}$ \\
\hline
\end{tabular}

The assessment of cardiac function of minipigs with MI or sham operation at 1 month after myoblast transplantation, control treatment $(\mathrm{NC})$ or left untreated. $* P<0.05$ vs. control treatment group. LVIDd: left ventricular end-diastolic internal diameter; LVIDs: left ventricular end-systolic internal diameter; LVEDV: left ventricular end-diastolic volume; LVESV: left ventricular end-systolic volume; FS: fractional shortening; EF: ejection fraction; LVPWs: Left ventricular end-systolic posterior wall thickness; LVPWd: Left ventricular end-diastolic posterior wall thickness.

Genomes (KEGG) pathway. GO and pathway analysis showed top 30 significant pathways involving DEGs, some of which were closely consistent with downregulated genes mentioned above (Figure $3 \mathrm{~B}$ and $3 \mathrm{C}$ ). These results reveal that myoblast transplantation can suppress the expression of pro-inflammatory gene in heart tissue post-MI.

\section{Myoblasts attenuate inflammatory responses post-MI}

Next we investigated the effect of myoblast transplantation on inflammatory responses in heart tissue post-MI. Immunofluorescence staining showed that the infiltration of CD11b positive inflammatory cells (monocytes/macrophages) was significantly decreased in heart tissue from myoblast transplantation group after MI compared with control treatment group (Figure 4A). Furthermore, immunohistochemistry staining showed that IL-1 $\beta$ production was also markedly suppressed in heart tissue of minipig post-MI with myoblast transplantation (Figure 4B). The expression levels of cytokines were further detected in remote, border and infarct zone of heart tissue with or without myoblast transplantation. As shown in Figure 4C, the mRNA expression levels of Il1b, Tnf and Il6 were significantly down-regulated in border and infarct zone, while the expression of anti-inflammatory cytokine gene $I l 10$ was up-regulated in remote and border zone of heart tissue with myoblast transplantation, indicating that the grafted myoblasts can enhance the expression of anti-inflammatory cytokine IL-10 and in turn inhibit inflammatory cytokine production triggered by MI.

As we known, DAMPs including HMGB1 and HSP60 were released to trigger sterile inflammation after MI $[24,25]$. The principle cells which recognize DAMPs and produce inflammatory cytokines post-MI are macrophages [26]. So we utilized a co-culture system with human myoblasts and human macrophage cell line THP1 to explore the effect of myoblasts on DAMP-triggered production of inflammatory cytokines in macrophage. As shown in Figure 5A-5C, the mRNA and protein expression levels of IL- $1 \beta$ and TNF- $\alpha$ triggered by recombinational human HMGB1 (rhHMGB1) and recombinational HSP60 (rhHSP60) in THP-1 cells were significantly decreased when co-culturing with myoblasts in a cell numberdependent manner. However, co-culture with myoblasts had no obvious effect on IL-6 production triggered by rhHMGB1 and rhHSP60 in THP-1 cells (data not shown). In addition, myoblasts co-culture significantly promoted IL-10 production triggered by rhHMGB1 and rhHSP60 in THP-1 cells (Figure 5A-5C), which is consistent with the in vivo data from myoblast transplantation (Figure $3 \mathrm{~A}$ and Figure 4C). What's more, we found that IL-10 blocking antibody treatment abolished the inhibitory effect of myoblast co-culture on the production of IL-1 $\beta$ and TNF-a triggered by rhHMGB1 in THP-1 cells (Figure 5D), confirming that the decreased production of inflammatory cytokines in macrophages co-cultured with myoblasts is attributed to the increased IL-10 production.

\section{Myoblasts inhibit the activation of MAPK and NF-kB pathway}

Previous studies have demonstrated that MAPK and NF-kB signaling pathway are required for sterile inflammation activation post-MI [26], we then investigated whether myoblast transplantation affected MAPK and NF-kB pathway activation. The phosphorylation levels of ERK, JNK, p38 and p65 were markedly decreased in heart tissue from minipig post-MI with myoblast transplantation compared with control treatment group (Figure 6A). Furthermore, co-culture with myoblasts also impaired the phosphorylation levels of ERK, JNK, p38 and p65 triggered by rhHMGB1 in THP-1 cells 


\section{A}

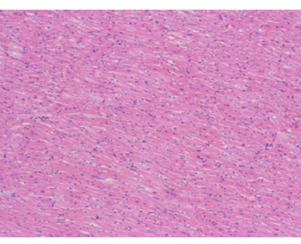

sham

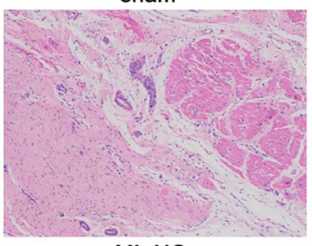

$\mathrm{Ml}+\mathrm{NC}$

C

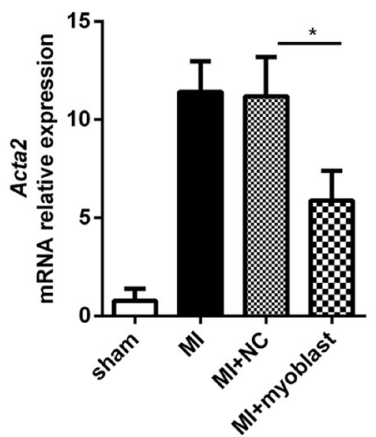

B

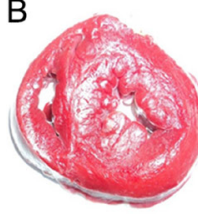

sham

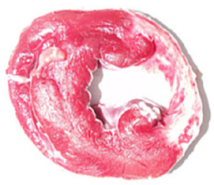

$\mathrm{MI+NC}$

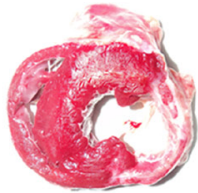

MI

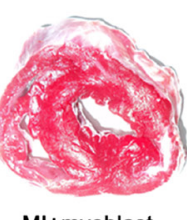

Ml+myoblast
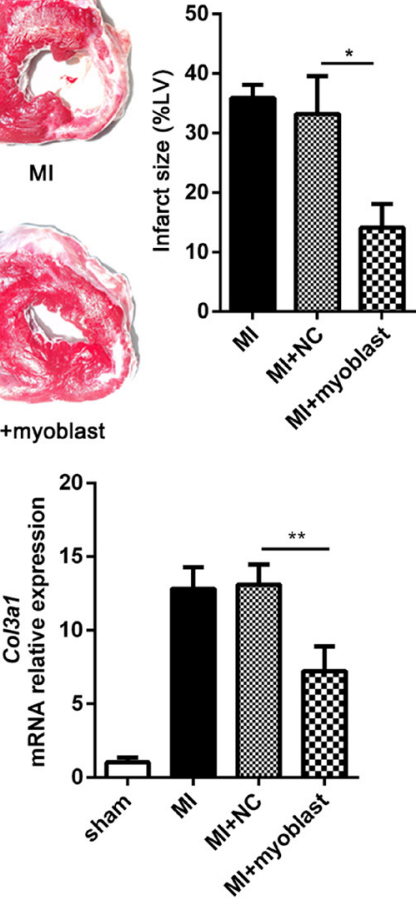
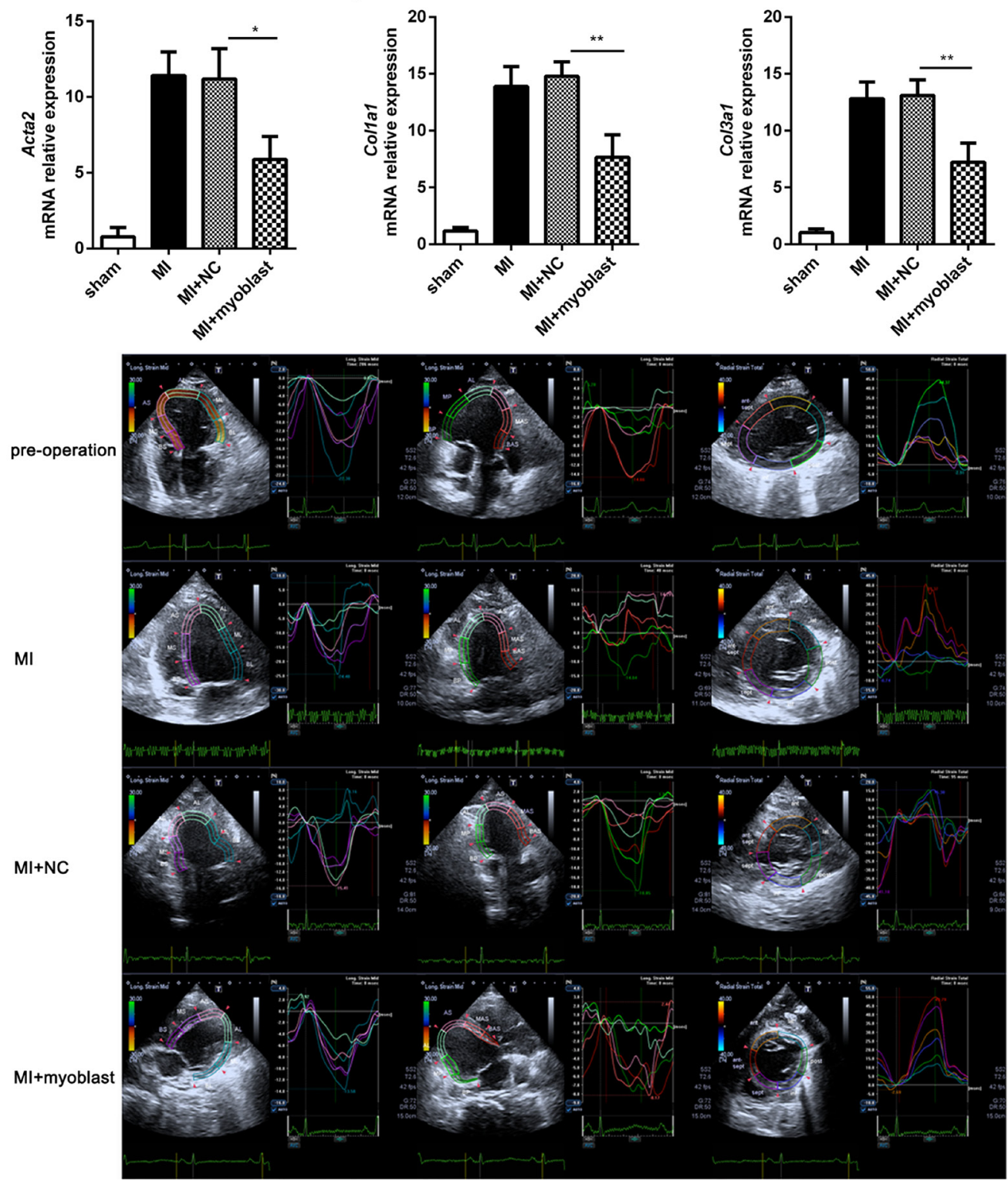

Figure 2: Myoblast transplantation improves cardiac function post-MI. (A) Representative HE staining images of heart sections from minipigs with MI or sham operation at 1 month after myoblast transplantation, control treatment or left untreated. (B) Representative TTC staining images of heart left ventricular sections from minipigs treated as in (A), and infarct size was measured and showed as a percentage of total area of left ventricular myocardium. (C) Q-PCR analysis of the expression of Acta2, Collal and Col3al in heart tissues from minipigs treated as in (A). (D) The measurement of longitudinal (left and middle panels) and radial (right panel) strain by $2 \mathrm{D}-\mathrm{STE}$ of cardiac function of minipigs treated as in (A). $\mathrm{n}=6$. Data are representative (A, B left, D), or mean \pm SEM (B right, C) of 3 individual experiments. ${ }^{*} P<0.05,{ }^{* *} P<0.01$. 
Table 2: The differentially expressed inflammation-relative genes in heart tissue of minipigs treated with or without myoblast transplantation post-MI

\begin{tabular}{|c|c|c|}
\hline Gene_Symbol & Gene_Title & $\begin{array}{l}\text { Fold change (Myo/ } \\
\text { NC) }\end{array}$ \\
\hline LOC100525766 & serine/threonine-protein kinase PAK 1-like & 0.018209086 \\
\hline ADIPOQ & adiponectin, C1Q and collagen domain containing & 0.039351824 \\
\hline TLR4 & Toll-like receptor 4 & 0.053853831 \\
\hline LOC100515801 & Uncharacterized protein KIAA1383 homolog & 0.07255373 \\
\hline IL1B & Interleukin 1 beta & 0.154663889 \\
\hline LOC100519703 & proteinase-activated receptor 2-like & 0.185482438 \\
\hline TNF & Tumor necrosis factor & 0.189656668 \\
\hline LBP & lipopolysaccharide binding protein & 0.22179613 \\
\hline LOC100512070 & glucose-6-phosphatase 3-like & 0.251654884 \\
\hline LOC100154770 & radiation-inducible immediate-early gene IEX-1-like & 0.287977899 \\
\hline LOC100525766 & serine/threonine-protein kinase PAK 1-like & 0.293721545 \\
\hline ACSL6 & acyl-CoA synthetase long-chain family member 6 & 0.29759855 \\
\hline PRL & prolactin & 0.307770743 \\
\hline GATA3 & GATA binding protein 3 & 0.311184563 \\
\hline ADRA1B & adrenoceptor alpha 1B & 0.339089567 \\
\hline RHOB & ras homolog family member B & 0.339561077 \\
\hline PPARGC-1 & peroxisome proliferator activated receptor gamma, coactivator 1 alpha & 0.345113903 \\
\hline IGF1R & insulin-like growth factor 1 receptor & 0.364555886 \\
\hline AMHR2 & anti-Mullerian hormone receptor, type II & 0.369864566 \\
\hline COL3A1 & Collagen, type III, alpha 1 & 0.370578657 \\
\hline LOC100155615 & vasopressin-induced protein, $32 \mathrm{kDa}$ & 0.377345245 \\
\hline CAMK2G & calcium/calmodulin-dependent protein kinase II gamma & 0.381822705 \\
\hline SLA-DRB1 & MHC class II histocompatibility antigen SLA-DRB1 & 0.387633403 \\
\hline ACCN2 & acid-sensing (proton-gated) ion channel 1 & 0.391439296 \\
\hline MAPK8 & Mitogen-activated protein kinase $8, \mathrm{JNK} 1$ & 0.396123721 \\
\hline LBP & lipopolysaccharide binding protein & 0.400341256 \\
\hline E2F7 & E2F transcription factor 7 & 0.401168991 \\
\hline LOC100621324 & heat shock-related $70 \mathrm{kDa}$ protein 2-like & 0.411213633 \\
\hline OLR1 & oxidized low density lipoprotein (lectin-like) receptor 1 & 0.416144478 \\
\hline LOC100523833 & fibroblast growth factor 13-like & 0.419831988 \\
\hline BDNF & brain-derived neurotrophic factor & 0.42688193 \\
\hline F3 & coagulation factor III (thromboplastin, tissue factor) & 0.439591227 \\
\hline PLAA & phospholipase A2-activating protein & 0.446603047 \\
\hline TGFB2 & transforming growth factor, beta 2 & 0.461156871 \\
\hline RORA & RAR-related orphan receptor A & 0.46211275 \\
\hline FOXO1 & forkhead box O1 & 0.462757924 \\
\hline SERPINE1 & $\begin{array}{l}\text { serpin peptidase inhibitor, clade } \mathrm{E} \text { (nexin, plasminogen activator inhibitor type } \\
\text { 1), member } 1\end{array}$ & 0.463425071 \\
\hline RACGAP1 & Rac GTPase activating protein 1 & 0.47786811 \\
\hline GATA3 & GATA binding protein 3 & 0.487248416 \\
\hline IQGAP3 & IQ motif containing GTPase activating protein 3 & 0.488153338 \\
\hline APOA2 & apolipoprotein A-II & 0.49103491 \\
\hline ANK3 & ankyrin 3, node of Ranvier (ankyrin G) & 0.49244312 \\
\hline SYNGAP1 & synaptic Ras GTPase activating protein 1 & 0.496903153 \\
\hline HYAL2 & hyaluronoglucosaminidase 2 & 0.498768065 \\
\hline LOC100738351 & microtubule-associated protein tau-like & 0.499859657 \\
\hline HIF1A & $\begin{array}{l}\text { hypoxia inducible factor 1, alpha subunit (basic helix-loop-helix transcription } \\
\text { factor) }\end{array}$ & 2.006498392 \\
\hline
\end{tabular}




\begin{tabular}{|c|c|c|}
\hline LOC100515801 & uncharacterized protein KIAA1383 homolog & 2.027618033 \\
\hline HMGB1 & high mobility group box 1 & 2.07995541 \\
\hline FOS & FBJ murine osteosarcoma viral oncogene homolog & 2.108144854 \\
\hline CYP2J34 & cytochrome P450, family 2 , subfamily J, polypeptide 34 & 2.139775885 \\
\hline DUSP6 & dual specificity phosphatase 6 & 2.205287882 \\
\hline LTB & lymphotoxin beta (TNF superfamily, member 3) & 2.259628027 \\
\hline B4GALT1 & UDP-Gal:betaGlcNAc beta 1,4- galactosyltransferase, polypeptide 1 & 2.280422277 \\
\hline THBS1 & Thrombospondin 1 & 2.325687086 \\
\hline THBS1 & thrombospondin 1 & 2.356147732 \\
\hline HSPA8 & heat shock $70 \mathrm{kDa}$ protein 8 & 2.36804402 \\
\hline DUSP6 & dual specificity phosphatase 6 & 2.421761848 \\
\hline SYK & spleen tyrosine kinase & 2.422838934 \\
\hline $\mathrm{CD} 40$ & CD40 molecule, TNF receptor superfamily member 5 & 2.478801936 \\
\hline CHI3L1 & chitinase 3-like 1 (cartilage glycoprotein-39) & 2.502965317 \\
\hline LOC100514374 & dual specificity protein phosphatase 4-like & 2.606314171 \\
\hline CPT1A & carnitine palmitoyltransferase 1A (liver) & 2.609206269 \\
\hline ELK4 & ETS-domain protein (SRF accessory protein 1) & 2.812234501 \\
\hline $\mathrm{C} 3$ & complement component 3 & 2.877851202 \\
\hline ADA & adenosine deaminase & 2.901005438 \\
\hline LOC100519703 & Proteinase-activated receptor 2-like & 3.230116054 \\
\hline ACP5 & acid phosphatase 5 , tartrate resistant & 3.33994883 \\
\hline IL10 & interleukin 10 & 3.394530387 \\
\hline LOC100518643 & Interleukin-33-like & 3.693850557 \\
\hline ALOX5AP & arachidonate 5-lipoxygenase-activating protein & 3.733013174 \\
\hline CPT1C & carnitine palmitoyltransferase $1 \mathrm{C}$ & 3.738067187 \\
\hline THBS1 & thrombospondin 1 & 4.004670655 \\
\hline FGFR2 & fibroblast growth factor receptor 2 & 4.566747424 \\
\hline MME & membrane metallo-endopeptidase & 4.625607971 \\
\hline CXCL14 & chemokine (C-X-C motif) ligand 14 & 5.54041483 \\
\hline CCL21 & chemokine (C-C motif) ligand 21 & 5.607199497 \\
\hline CCL2 & chemokine (C-C motif) ligand 2 & 5.630495932 \\
\hline LPAR2 & lysophosphatidic acid receptor 2 & 6.141604456 \\
\hline CXCL14 & chemokine (C-X-C motif) ligand 14 & 7.729290554 \\
\hline S100A9 & S100 calcium binding protein A9 & 8.279375777 \\
\hline NTRK3 & Neurotrophic tyrosine kinase, receptor, type 3 & 10.19038462 \\
\hline THBS1 & thrombospondin 1 & 14.95862849 \\
\hline
\end{tabular}

Myo: myoblasts; NC, control treatment group.

(Figure 6B). The results indicate that the impaired activation of MAPK and NF- $\mathrm{KB}$ signaling is contributed to the suppressed inflammatory response mediated by myoblast transplantation after MI.

\section{DISCUSSION}

The in-depth study of the mechanism by which myoblasts improves cardiac function post-MI will benefit the application of myoblast transplantation. In this study, we found that the grafted myoblasts survived successfully in peri-infarct area and had important roles in promoting infarct healing and improving cardiac function. Microarray analysis indicated that many inflammation-related genes differentially expressed in peri-infarct heart tissues between groups of myoblast transplantation and control treatment, especially some pro-inflammatory cytokines down-regulated and anti-inflammatory cytokines upregulated in myoblast transplantation group. Our study further demonstrates the novel function of myoblasts in the negative regulation of inflammatory response and uncovers the close relationship between inflammation and cardiac function after myoblast transplantation post-MI, which will has an instructional effect on the future clinical study.

Sterile inflammation induced by ischemia heart injury is a critical component of tissue healing. However, 


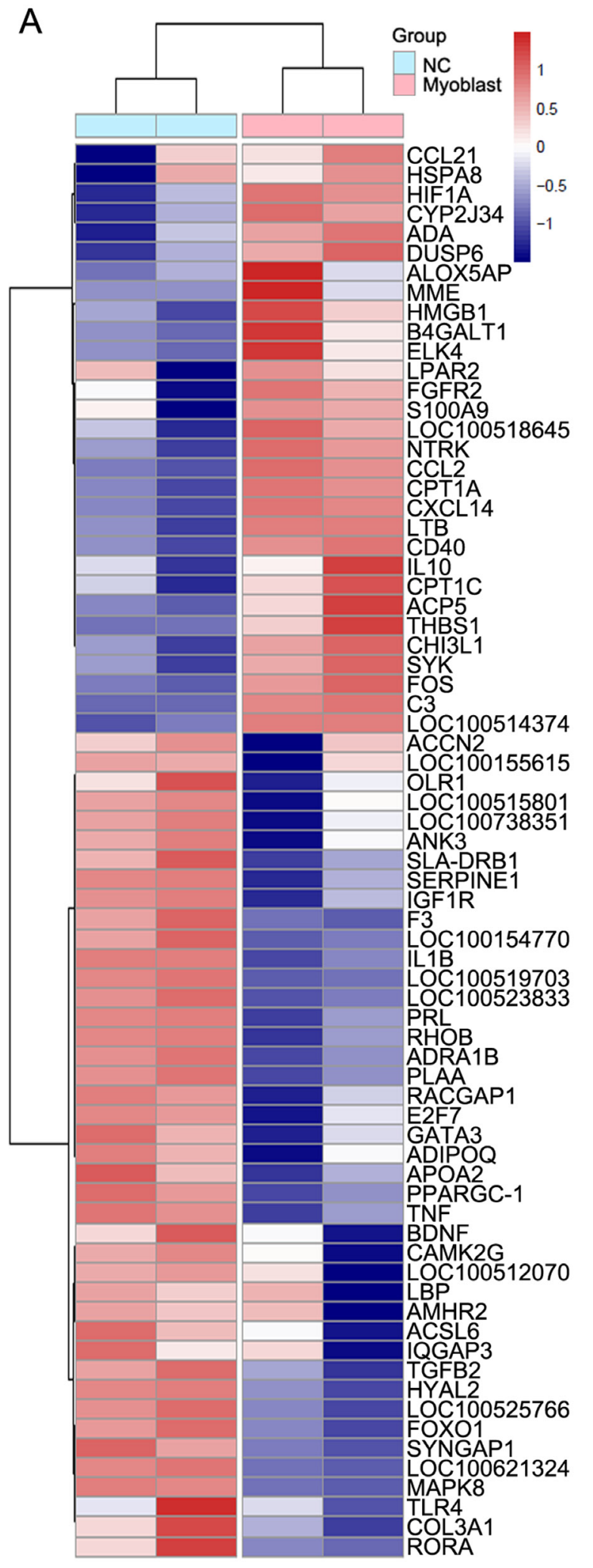

B GO enrichment

GO:0051897 positive regulation of protein kinase B... GO:0007507 heart development

GO:0006351 transcription. DNA-templated

GO:0030308 negative regulation of cell growth

GO:0030593 neutrophil chemotaxis

GO:0001666 response to hypoxia

GO:0051781 positive regulation of cell division

GO:0010575 positive regulation of VEGF production

GO:0001764 neuron migration

GO:0090090 negative regulation of canonical Wnt signaling...

GO:0071356 cellular response to tumor necrosis factor

GO:0090263 positive regulation of canonical Wnt signaling... 8

GO:0030855 epithelial cell differentiation

GO:0042060 wound healing

GO:0050829 defense response to Gram-negative bacterium

GO:0007059 chromosome segregation

GO:0045087 innate immune response

GO:0071347 cellular response to interleukin-1

GO:0043524 negative regulation of neuron apoptotic process

GO:0060348 bone development

GO:0035690 cellular response to drug

GO:0006955 immune response

GO:0001701 in utero embryonic development

GO:0001657 ureteric bud development

GO:0000187 activation of MAPK activity

GO:0006355 regulation of transcription, DNA-templated

GO:0030154 cell differentiation

GO:0043065 positive regulation of apoptotic process

GO:0071222 cellular response to lipopolysaccharide

GO:0006954 inflammatory response

\begin{tabular}{cccc}
1 & 1 & 1 & 16 \\
\hline 0 & 1 & $-\log 10($ Pvalue $)$ & 3
\end{tabular}

C

\section{Pathway enrichment}

ssc04610:Complement and coagulation cascades ssc05144:Malaria

ssc05323:Rheumatoid arthritis

ssc03320:PPAR signaling pathway

ssc05140:Leishmaniasis

ssc05150:Staphylococcus aureus infection

ssc05133: Pertussis

ssc04145:Phagosome

ssc05152:Tuberculosis

ssc05322: Systemic lupus erythematosus

ssc04940:Type I diabetes mellitus

ssc04066: HIF-1 signaling pathway

ssc04350:TGF-beta signaling pathway

ssc04612:Antigen processing and presentation

ssc05142:Chagas disease (American trypanosomiasis)

ssc05330:Allograft rejection

ssc05134:Legionellosis

ssc05416:Viral myocarditis

ssc05202:Transcriptional misregulation in cancer

ssc05145:Toxoplasmosis

ssc04514:Cell adhesion molecules (CAMs)

ssc05146:Amoebiasis

ssc04974:Protein digestion and absorption

ssc04964:Proximal tubule bicarbonate reclamation

ssc04668:TNF signaling pathway

ssc05020:Prion diseases

ssc01212:Fatty acid metabolism

ssc05143:African trypanosomiasis

ssc05332:Graft-versus-host disease

ssc04064:NF-kappa B signaling pathway

\begin{tabular}{ccccc}
1 & \multicolumn{1}{c}{11} \\
\hline 0 & 2 & 4 & 6 & 8
\end{tabular}

Figure 3: The expression profiles of inflammation-relative genes in heart tissues after myoblast transplantation. (A) Heatmap showing 72 differentially expressed inflammation-related genes in heart tissues from minipigs with MI followed by myoblast transplantation or control treatment (NC). Red means an increase in expression level, whereas blue represents a decrease in expression level in each group. (B) GO enrichment analysis of differentially expressed genes. (C) KEGG enrichment analysis of differentially expressed genes. 
A

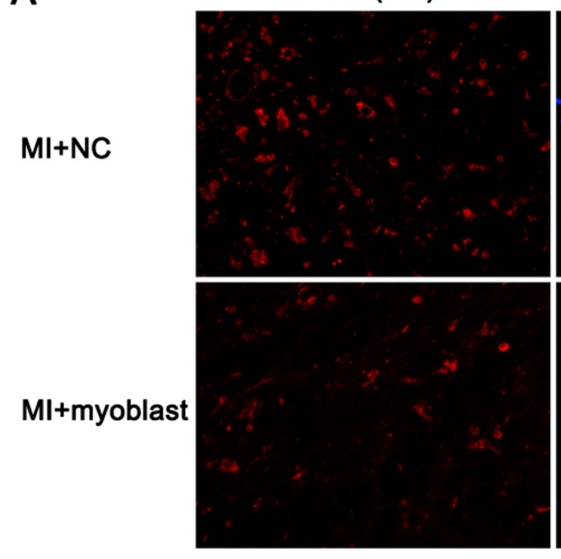

B

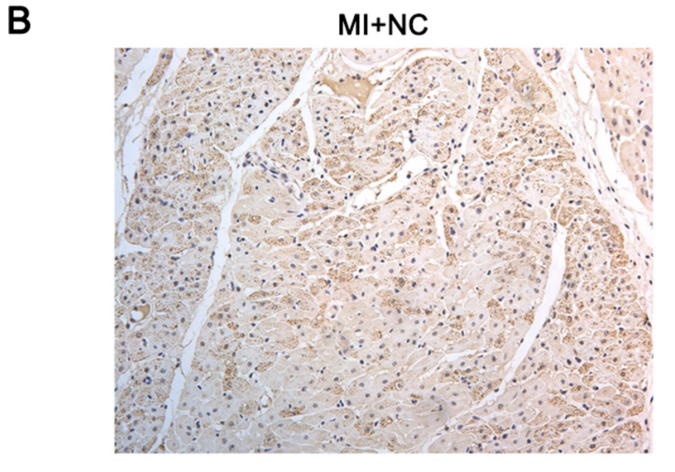

C
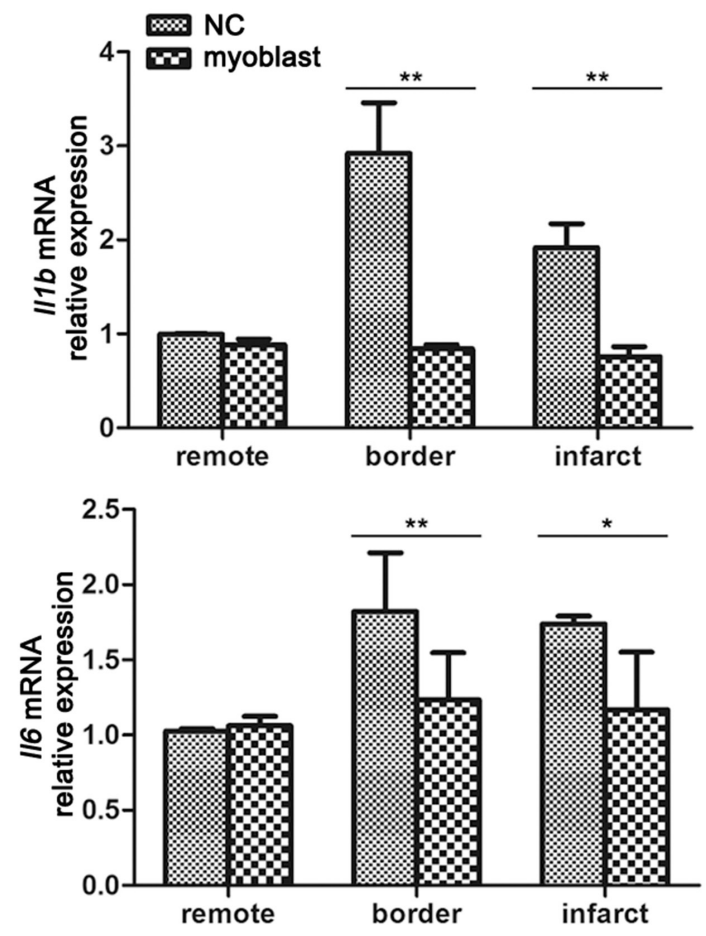

DAPI
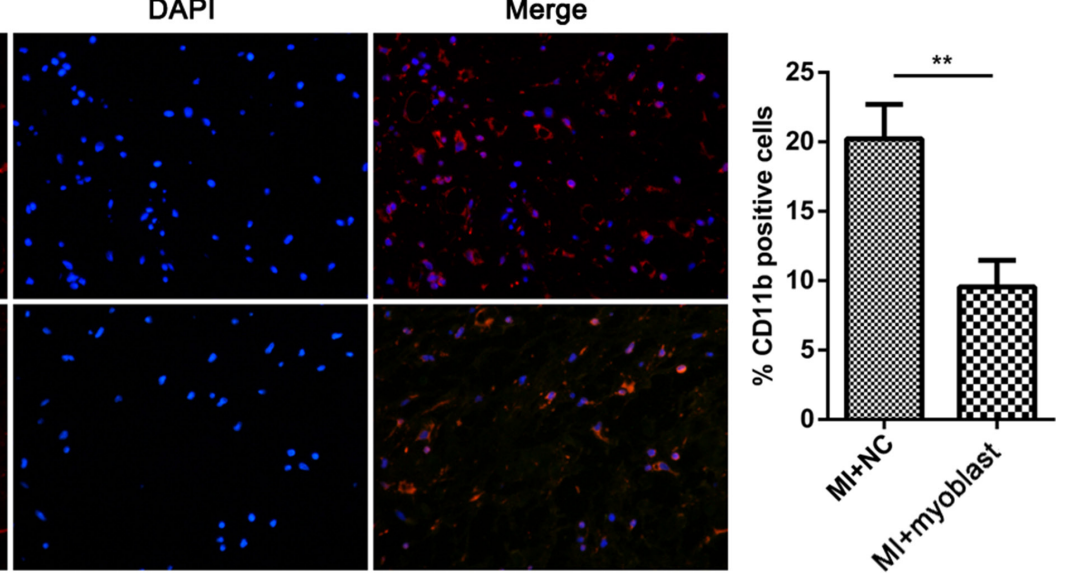

Ml+myoblast
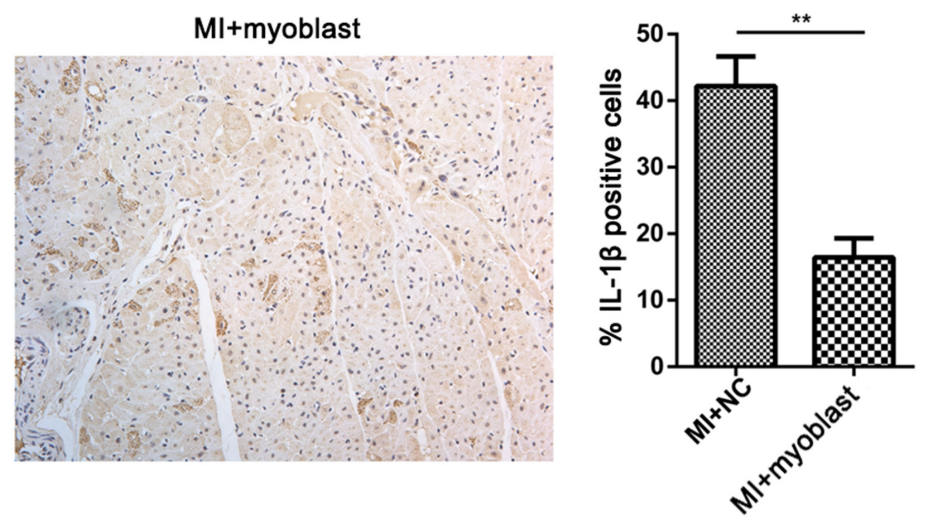
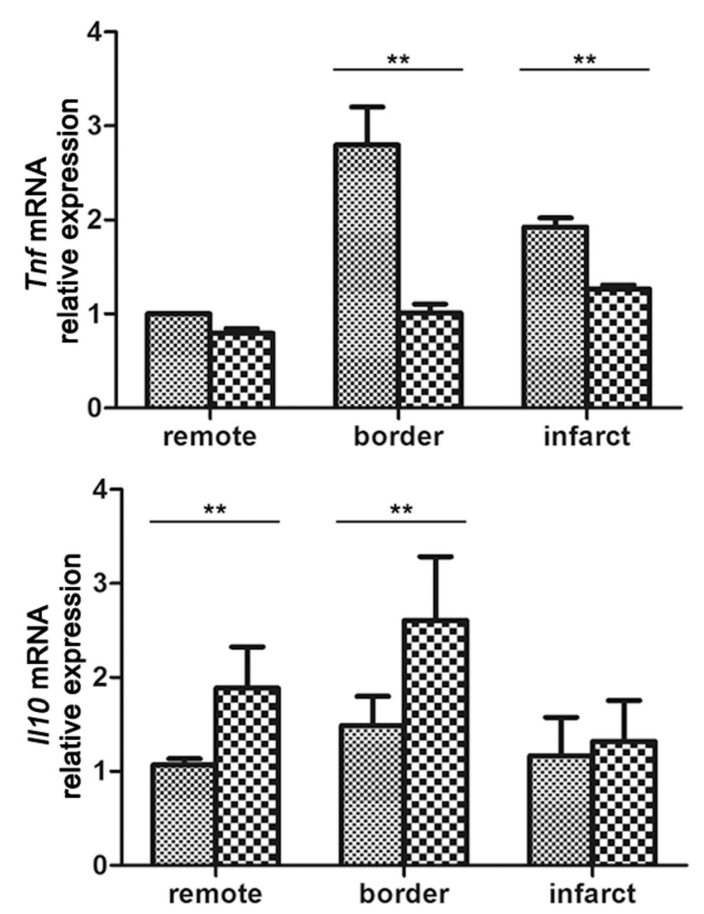

Figure 4: Myoblast transplantation attenuates inflammation in heart tissue post-MI. (A) Immunofluorescence analysis of CD11b in heart sections from minipigs with MI followed by myoblast transplantation or control treatment (NC), and quantification of CD11b-positive cells is showed as a percentage of total cells counted. (B) Immunohistochemical staining of IL-1b in heart sections from minipigs treated as in (A), and quantification of IL-1b-positive cells is showed as a percentage of total cells counted. Original magnification, $\times 400$. (C) Q-PCR analysis of the mRNA expression of IL-1 $\beta$, TNF- $\alpha$, IL-6 and IL-10 in different zones of heart tissues from minipigs treated as in (A). $n=6$. Data are representative (A left, B left), or mean \pm SEM (A right, B right, C) of 3 individual experiments. $* P<0.05$, $* * P<0.01$. 
excessive activation of inflammation-related processes leads to adverse LV remodeling after MI. Some preclinical studies indicate that the expression levels of pro-inflammatory cytokines IL-6, TNF- $\alpha$ and IL- $1 \beta$ are closely associated with LV end-diastolic diameter measured at study termination [27]. One multicenter clinical trial of 1,200 patients with progressed heart failure shows that the up-regulated circulating levels of TNF, IL-6 and the soluble TNF receptors sTNFR1 and
sTNFR2 are related with increased mortality [28]. Thus, inhibition of the myocardial inflammation is effective to attenuate cardiac dysfunction and prevent adverse cardiac remodeling after MI.

The injury incurred by cardiac myocytes and the extracellular matrix consequent to acute ischemic damage rapidly release DAMPs, which play a critical role in the sterile inflammatory response in MI by binding to pattern recognition receptors on or in cells of the innate immune
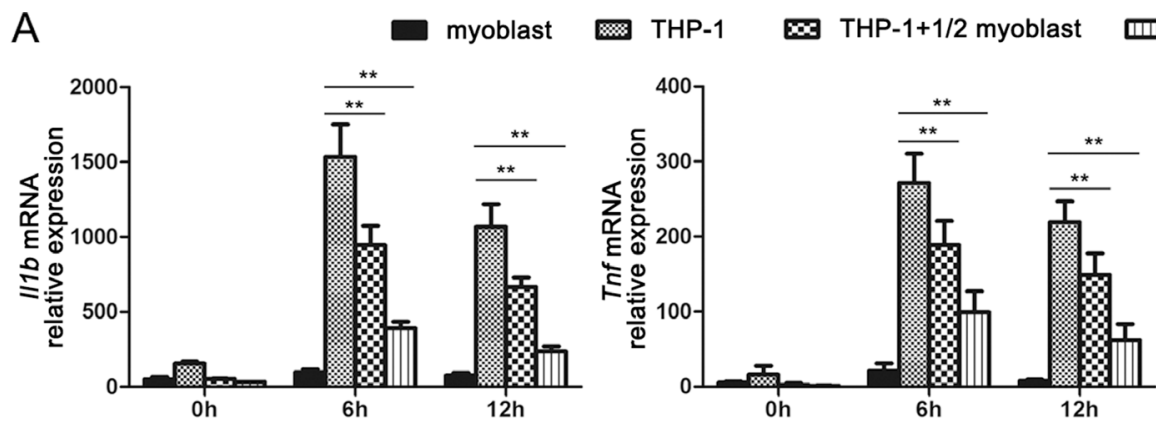

THP-1+myoblast

B

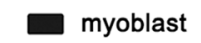

THP-1

$\infty$ THP-1+1/2 myoblast
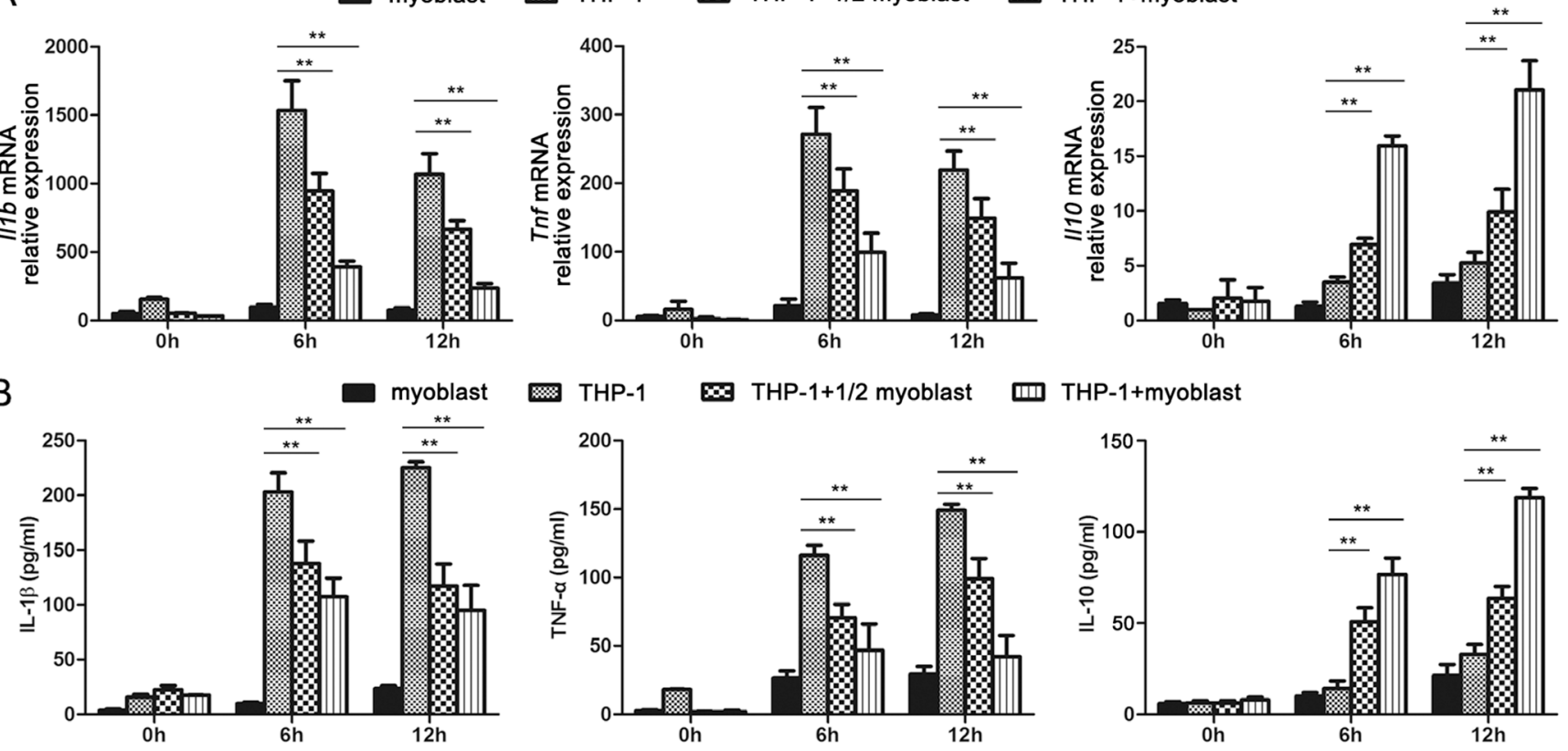

THP-1+myoblast

C
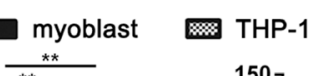

$\infty$ THP-1+1/2 myoblast
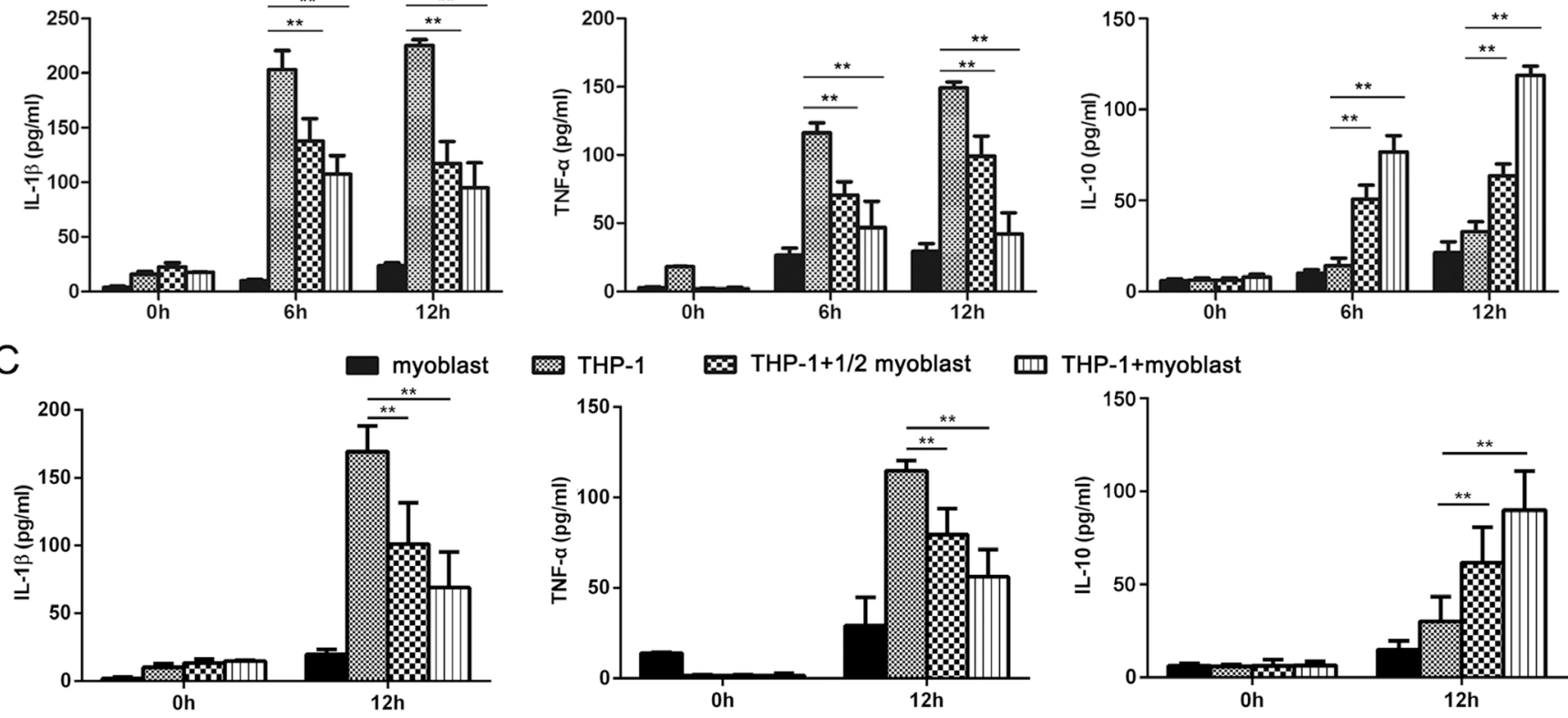

THP-1+myoblast
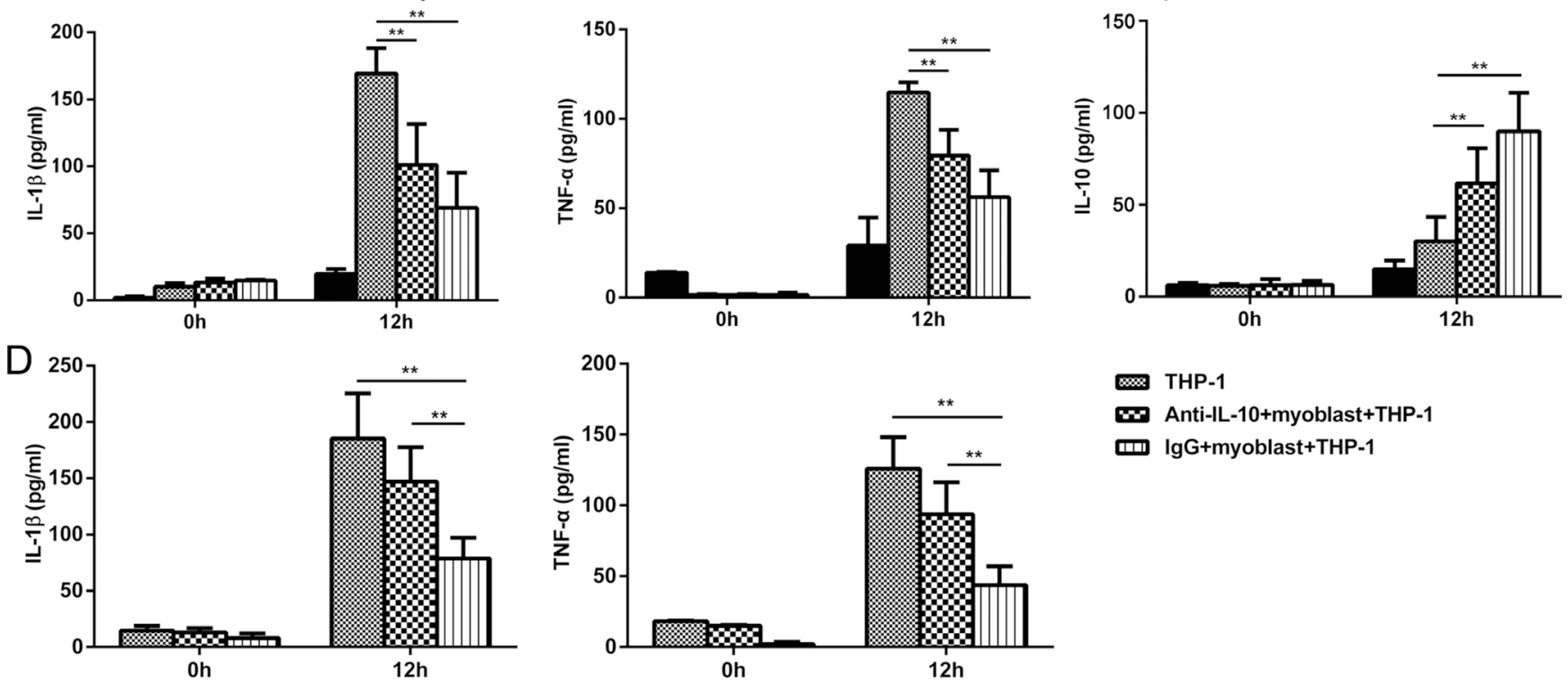

THP-1

Anti-IL-10+myoblast+THP-1 Ig Ig+myoblast+THP-1

Figure 5: Myoblast co-culture decreases inflammatory cytokine production but increases IL-10 production triggered by DAMPs in THP-1 cells. (A-C) THP-1 cells were cultured alone or co-cultured with the half or same number of myoblasts, and then stimulated with rhHMGB1 (A, B) or rhHSP60 (C) for the indicated times, the mRNA (A) and protein (B, C) expression levels of IL-1 $\beta$, TNF- $\alpha$ and IL-10 were detected by Q-PCR analysis (A) and ELISA (B, C) respectively. (D) THP-1 cells were cultured alone or co-cultured with the same number of myoblasts, and then treated with IL-10 blocking antibody or IgG. The production of IL-1 $\beta$ and TNF- $\alpha$ triggered by rhHMGB1 in supernatant was detected by ELISA. Data are mean \pm SEM of 3 individual experiments. ${ }^{* *} P<0.01$. 
system [29]. TLR4 is a key pattern recognition receptor, which can bind several DAMPs and initiates multiple inflammatory cascades [30]. In our microarray data, the expression of TLR4, as well as its downstream signal molecule MAPK8, significantly decreased in peri-infarct heart tissues with myoblast transplantation, which suggest that myoblasts limit recruitment of inflammatory cells to the injured myocardium and attenuate activation of inflammatory signal pathway. Forkhead box O1 (FOXO1), a transcription factor that functions in the regulation of cell proliferation, apoptosis and cardiovascular function. FOXO1 can promote inflammatory responses in innate immune cells triggered by TLR4 [31,32]. Our microarray data found that FOXO1 expression was decreased in heart tissue with myoblast transplantation. These results suggest that FOXO1 may also be involved in the inhibition of inflammation mediated by grafted myoblasts. Thus, except for higher IL-10 production, the decreased expression of inflammation-related protein and suppressed activation of signaling pathway also attribute to the limited inflammation in heart tissue of minipig with myoblast transplantation.

Monocytes and macrophages are emerging as key players in mediating both the pathogen responses and sterile inflammation including that arising from ischemia heart injury $[26,33]$. Cardiac macrophages are abundant in heart tissue after MI, which are mainly derived from circulating monocytes produced by the haematopoietic system and are centrally involved in inflammatory tissue remodeling, resolution of inflammation during post-MI healing, and left ventricular remodeling [26]. In our study, we demonstrate that myoblasts inhibit DAMP-triggered production of pro-inflammatory cytokines in macrophages through the increased IL-10 production in vitro co-culture system, together with the higher IL-10 gene expression in heart tissue with myoblast transplantation, our results suggest that myoblasts inhibit the inflammatory cytokine production in immune cells mainly including monocytes and macrophages in heart tissue through the higher IL10 level and decreased activation of inflammation-related signaling pathway.

In summary, myoblasts have been shown as a most possible cell source for clinical applications such as ischemic cardiomyopathy through recent advances in research [34-36]. Our study further uncovers the novel mechanism underlying the improved cardiac function and prevention of adverse cardiac remodeling mediated by myoblast transplantation. The change of grafted cell number and implantation of myoblasts genetically engineered to over-express some factors will acquire more attractive and dramatic improvement in myoblast therapy.

\section{MATERIALS AND METHODS}

\section{Cell culture}

Human THP-1 cells were from the American Type Culture Collection and cultured in RPMI-1640 medium (Corning, Manassas, VA) supplemented with $10 \%$ fetal bovine serum (Gibco, Paisley, PA). Male human skeletal
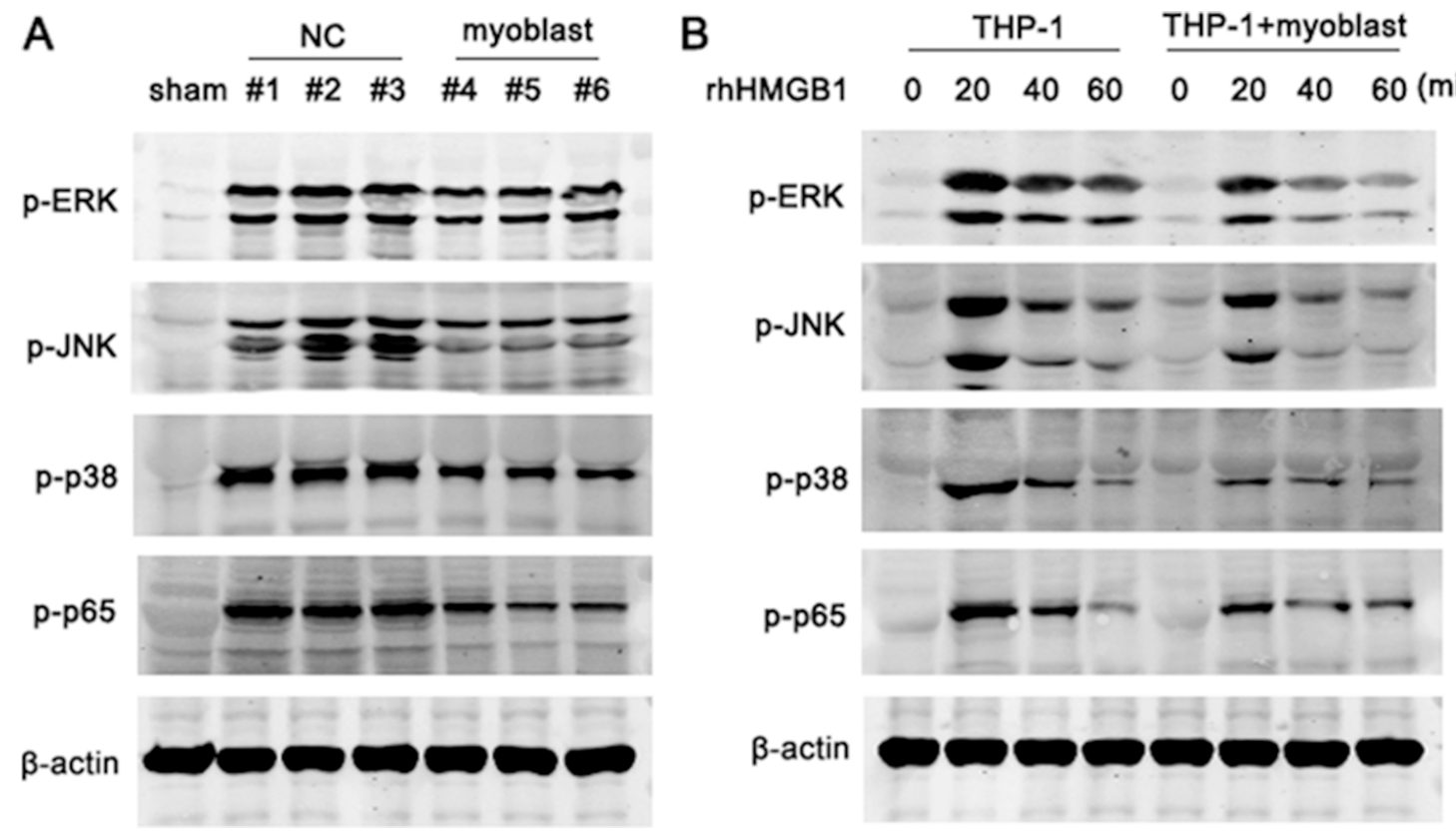

Figure 6: Myoblast inhibits the activation of MAPK and NF-kB pathway. (A) Immunoblotting analysis of phosphorylation (p-) levels of ERK, JNK, p38 and p65 in lysates of heart tissues from minipigs with MI followed by myoblast transplantation or control treatment (NC). (B) Immunoblotting analysis of phosphorylation (p-) levels of ERK, JNK, p38, and p65 in lysates of THP-1 cells cultured alone or co-cultured with myoblasts followed by treatment with rHMGB1 for the indicated times. Data are representative of 3 individual experiments. 
myoblasts were provided by the Cell Therapy Institute of Wuhan in China, and were cultured in Dulbecco's modified Eagle's medium (DMEM) (Corning) with $4.5 \mathrm{~g} / \mathrm{L}$ of glucose. Cells were maintained in standard cell culture environment $\left(95 \%\right.$ humidity, $5 \% \mathrm{CO} 2$ at $\left.37^{\circ} \mathrm{C}\right)$. Before transplantation, myoblasts were harvested and suspended in DMEM medium without phenol red and enriched in 2\% BSA (Sigma-Aldrich, USA). Final concentration of myoblasts was $10^{4} / \mu 1$ of DMEM.

\section{Animal model and myoblast transplantation}

Four-month-old Female Chinese Bama minipigs (16-20 kg) were from Taihe Biotechnology Co. (Taizhou, China). All minipigs were clinically healthy, housed in the animal facility under standard conditions and received humane care. All animal experiments were performed according to the National Institute of Health Guide for the Care and Use of Laboratory Animals, with the approval of the Scientific Investigation Board of Tongji University, Shanghai. Female minipigs were inductively anesthetized by intramuscular injection with midazolam $(2 \mathrm{ml}: 2 \mathrm{mg})$ and ketamine $(2 \mathrm{ml}: 0.1$ $\mathrm{mg}$ ), then endotracheal intubated, lastly connected to a ventilator (fre 20 TV 400ml I:E 1:1.5 FiO2 40\%) assisted by propofol pump (20 ml:200 $\mathrm{mg}$ ) for intra-operative maintain. Transthoracic small incision on left fourth intercostal space makes left circumflex (LCx) coronary artery visualized. There was no distinctive anatomic variation of LCx among the experiment minipigs. Preventative ligation (used a silk tie placed around the proximal LCx to reduce the outer diameter of the artery such that resting flow through the stenotic region was decreased by $80 \%$, in this way tied 2 minutes and untied for 5 minutes) was performed three to five times, intravenous lidocaine was included in case of ventricular arrhythmia. Model of myocardial infarction was finally established by permanent ligation beyond the root of left circumflex coronary artery. After MI, $5 \mathrm{ml}$ DMEM with or without $5 \times 10^{7}$ myoblasts were intramyocardially injected into the promising infarct border zone with 10 separate injections using a 27-gauge needle. A total of 24 Bama minipigs were randomized into 4 groups $(\mathrm{n}=$ 6): Sham operation, MI group, DMEM injection after MI (control treatment), myoblast transplantation after MI. In addition, mice in control treatment group and myoblast transplantation group both received the same does of Cyclosporin A ( $5 \mathrm{mg} / \mathrm{kg}$ ) before myoblast transplantation, whereas mice in sham group and MI group did not received Cyclosporin A. Electrocardiographic recordings revealed the short arrhythmia episodes occurred in a few minipigs of myoblast transplantation group within 7 days after myoblast transplantation or control treatment group, but these were self-limited and haemodynamically well tolerated.

\section{Histology}

Triphenyl tetrazolium chloride (TTC) was used to determine the infarct size. Briefly, the whole heart was excised and quickly frozen for 20 minutes. The heart was cut into 5-10 $\mathrm{mm}$ transverse slices and then immersed in $1 \%-2 \%$ TTC solution for 30 minutes at $37^{\circ} \mathrm{C}$. After fixed in $4 \%$ formalin, the slices were taken photo by digital camera and the infarct size was analyzed by Image $\mathrm{J}$ (National Institutes of Health, Bethesda, MD). HE staining was performed to assess the myocardial cell proliferation and inflammatory cell infiltration. Briefly, the heart was harvested and fixed by 4\% paraformaldehyde, embedded in paraffin. Serial sections were cut into $6 \mu \mathrm{m}$ thickness and stained with hematoxylin \& eosin and then observed with Leica microscope. The heart sections were also subjected to immunohistochemistry staining with IL-1 $\beta$ antibody (ebioscience).

\section{Immunofluorescent analysis}

Minipig heart was excised and fixed by $4 \%$ paraformaldehyde. Serial sections were cut into $6 \mu \mathrm{m}$ thickness to prepare for immunofluorescence analysis. Sections were incubated with primary anti-human myosin heavy chain antibody (Millipore), anti-human histocompatibility antigen class I antibody (Abcam) and anti-minipig CD11b antibody (ebioscience) followed by incubation with Alexa Fluor-conjugated secondary antibody (Thermo Scientific). DAPI was used to label total cells. Cells were examined under a confocal laser microscope (Leica TCS SP5II STED, Mannheim, Germany).

\section{Two-dimensional speckle tracking echocardiography analysis}

Transthoracic Echocardiography was performed in the anesthetized minipigs using Vevo2100 (Visual Sonics VSI, Toronto, ON, Canada) with MS400 linear array transducer $(38 \mathrm{MHz})$. Cardiac function parameters were obtained from short-axis and long-axis views of speckle tracking echocardiography.

\section{Microarray analysis}

Total RNA was extracted using TRIZOL Reagent (Invitrogen, Carlsbad, CA) and checked for a RIN number to inspect RNA integrity by an Agilent Bioanalyzer 2100 (Agilent technologies, Santa Clara, CA). Qualified total RNA was further purified by RNeasy micro kit (QIAGEN, Hilden, Germany) and RNase-Free DNase Set (QIAGEN). Biotin-labeled cRNA was generated with the GeneChip 3'IVT Express Kit (Affymetrix, Santa Clara, CA) for the Affymetrix system, and then hybridized to GeneChip ${ }^{\circledR}$ 
Table 3: Q-PCR primers for detection of $\mathrm{mRNA}$ expression of cytokines

\begin{tabular}{|c|c|}
\hline Gene symbol & Primers \\
\hline Human $I L 1 b$ & $\begin{array}{c}\text { F: AGCTACGAATCTCCGACCAC } \\
\text { R: CGTTATCCCATGTGTCGAAGAA }\end{array}$ \\
\hline Human IL10 & $\begin{array}{c}\text { F: GACTTTAAGGGTTACCTGGGTTG } \\
\text { R: TCACATGCGCCTTGATGTCTG }\end{array}$ \\
\hline Human $T N F$ & $\begin{array}{l}\text { F: ATGAGCACTGAAAGCATGATCC } \\
\text { R: GAGGGCTGATTAGAGAGAGGTC }\end{array}$ \\
\hline Human Sry & $\begin{array}{l}\text { F:GCGTATTCAACAGCGATGATTAC } \\
\text { R:TCTCCCGTTTCACACTGATACTT }\end{array}$ \\
\hline Minipig $I l l b$ & $\begin{array}{l}\text { F: AGGTCCACATGGGCTGAAGAAC } \\
\text { R: GGCTGGCTTTGAGTGAGGAGAA }\end{array}$ \\
\hline Minipig $I l 10$ & $\begin{array}{l}\text { F: CTGAGAACAGCTGCATCCAC } \\
\text { R: TGGCTTTGTAGACACCCCTC }\end{array}$ \\
\hline Minipig $T n f$ & $\begin{array}{l}\text { F: GCTGTACCTCATCTACTCCC } \\
\text { R: TAGACCTGCCCAGATTCAGC }\end{array}$ \\
\hline
\end{tabular}

Porcine Genome Arrays (Affymetrix), containing 23,937 probe sets to examine 23,256 transcripts, and scanned by GeneChip ${ }^{\circledR}$ Scanner 3000 (Affymetrix, Santa Clara, CA) and Command Console Software 3.1 (Affymetrix, Santa Clara, CA). Raw data were normalized by MAS 5.0 algorithm, Gene Spring Software 11.0 (Agilent tech, Santa Clara, CA). The genes with significant differential expression (a fold change $>2$ ) between the 2 different groups were filtered.

GO analysis and KEGG analysis were applied to determine the biological roles of these differentially expressed mRNAs, based on the latest KEGG (Kyoto Encyclopedia of Genes and Genomes) database (http:// www.genome.jp/kegg/). Inflammation-related Genes annotated by GO terms (http://www.geneontology.org/) and KEGG pathway were filtrated out and visualized as a heatmap chart and scatter plot based on expression level. Array data are available at Gene Expression Omnibus (http://www.ncbi.nlm.nih.gov/geo/) under the accession number GSE 94151.

\section{RNA isolation and quantitative PCR}

Total RNA was isolated from heart tissues and cells using Trizol reagent (Invitrogen, Carlsbad, CA). cDNA was synthesized by reverse transcription synthesis kit (TOYOBO, Osaka, JAPAN). The expression of human $\mathrm{Y}$ chromosome was detected with the change of sex determining region $\mathrm{Y}$ (SRY). The gene expression levels of Tnf, Illb, Il6 and $I l 10$ were analyzed by quantitative PCR (Q-PCR) using SYBR Green PCR kit (TOYOBO, Osaka, Japan) and ABI 7900 (Applied Biosystems, Waltham, MA). The primers for the tested genes were purchased from JIELI Biology (Shanghai, China) and their sequences were showed in Table 3.

\section{Enzyme-linked immunosorbent assay (ELISA)}

Cytokine (IL-1 $\beta$, IL-6, IL-10, TNF- $\alpha$ ) production in supernatants of cell culture were assayed using ELISA kit (R\&D, Minneapolis, MN) according to manufacturer's instructions.

\section{Immunoblotting}

Heart tissues and cells were lysed with cell lysis buffer (Cell Signaling Technology) containing protease inhibitor mixture (Merck Millipore). Protein concentration of the extracts was measured with BCA assay (Thermo Fisher Scientific). Immunoblotting analysis was performed as described previously [37].

\section{Statistical analysis}

Data were presented as mean \pm standard error of the mean (SEM). The unpaired Student's $t$-test and oneway ANOVA were used to assess the significance of differences between data. $P<0.05$ was considered to be statistically significant.

\section{Authors' contributions}

BW, LZ, HC, JY, MW and YM planned, performed and analyzed experiments; HF reviewed the manuscript and provided advice; $\mathrm{ZZ}$ and $\mathrm{ZL}$ designed the overall research, analyzed experiments and wrote the manuscript.

\section{ACKNOWLEDGMENTS}

We thank Dr. Peter K. Law (Cell Therapy Institute of Wuhan, China) for providing human myoblasts. This work 
is supported by Grants from the National Natural Science Foundation of China (81373146, 81571541, 81370433), Basic Research Program of Science and Technology Commission of Shanghai Municipality (14JC1405200) and The national innovative research groups program of the National Natural Science Foundation of China (81521061).

\section{CONFLICTS OF INTEREST}

The authors declare that they have no conflicts of interest.

\section{REFERENCES}

1. Velagaleti RS, Pencina MJ, Murabito JM, Wang TJ, Parikh NI, D'Agostino RB, Levy D, Kannel WB, Vasan RS. Long-term trends in the incidence of heart failure after myocardial infarction. Circulation. 2008; 118:2057-2062.

2. Arslan F, de Kleijn DP, Pasterkamp G. Innate immune signaling in cardiac ischemia. Nat Rev Cardiol. 2011; 8:292-300.

3. Eltzschig HK, Eckle T. Ischemia and reperfusion--from mechanism to translation. Nat Med. 2011; 17:1391-1401.

4. Wrigley BJ, Lip GY, Shantsila E. The role of monocytes and inflammation in the pathophysiology of heart failure. Eur J Heart Fail. 2011; 13:1161-1171.

5. Kempf T, Zarbock A, Vestweber D, Wollert KC. Antiinflammatory mechanisms and therapeutic opportunities in myocardial infarct healing. J Mol Med (Berl). 2012; 90:361-369.

6. Rahel BM, Visseren FL, Suttorp MJ, Plokker TH, Kelder JC, de Jongh BM, Bouter KP, Diepersloot RJ. Preprocedural serum levels of acute-phase reactants and prognosis after percutaneous coronary intervention. Cardiovasc Res. 2003; 60:136-140.

7. Chan AW, Bhatt DL, Chew DP, Reginelli J, Schneider JP, Topol EJ, Ellis SG. Relation of inflammation, benefit of statins after percutaneous coronary interventions. Circulation. 2003; 107:1750-1756.

8. Schippers EF, Berbee JF, van Disseldorp IM, Versteegh MI, Havekes LM, Rensen PC, van Dissel JT. Preoperative apolipoprotein CI levels correlate positively with the proinflammatory response in patients experiencing endotoxemia following elective cardiac surgery. Intensive Care Med. 2008; 34:1492-1497.

9. Wollert KC, Drexler H. Cell therapy for the treatment of coronary heart disease: a critical appraisal. Nat Rev Cardiol. 2010; 7:204-215.

10. Burchfield JS, Iwasaki M, Koyanagi M, Urbich C, Rosenthal N, Zeiher AM, Dimmeler S. Interleukin-10 from transplanted bone marrow mononuclear cells contributes to cardiac protection after myocardial infarction. Circ Res. 2008; 103:203-211.
11. Girlovanu M, Susman S, Soritau O, Rus-Ciuca D, Melincovici C, Constantin AM, Mihu CM. Stem cells biological update and cell therapy progress. Clujul Med. 2015; 88:265-271.

12. Sanganalmath SK, Bolli R. Cell therapy for heart failure: a comprehensive overview of experimental and clinical studies, current challenges, and future directions. Circ Res. 2013; 113:810-834.

13. Orlic D, Kajstura J, Chimenti S, Bodine DM, Leri A, Anversa P. Bone marrow stem cells regenerate infarcted myocardium. Pediatr Transplant. 2003 (Suppl 3); 7:86-88.

14. Strauer BE, Brehm M, Zeus T, Kostering M, Hernandez A, Sorg RV, Kogler G, Wernet P. Repair of infarcted myocardium by autologous intracoronary mononuclear bone marrow cell transplantation in humans. Circulation. 2002; 106:1913-1918.

15. Taylor DA, Atkins BZ, Hungspreugs P, Jones TR, Reedy MC, Hutcheson KA, Glower DD, Kraus WE. Regenerating functional myocardium: improved performance after skeletal myoblast transplantation. Nat Med. 1998; 4:929-933.

16. Farahmand P, Lai TY, Weisel RD, Fazel S, Yau T, Menasche P, Li RK. Skeletal myoblasts preserve remote matrix architecture and global function when implanted early or late after coronary ligation into infarcted or remote myocardium. Circulation. 2008 (Suppl); 118:S130-137.

17. Fukushima S, Coppen SR, Lee J, Yamahara K, Felkin LE, Terracciano CM, Barton PJ, Yacoub MH, Suzuki K. Choice of cell-delivery route for skeletal myoblast transplantation for treating post-infarction chronic heart failure in rat. PLoS One. 2008; 3:e3071.

18. Ghostine S, Carrion C, Souza LC, Richard P, Bruneval P, Vilquin JT, Pouzet B, Schwartz K, Menasche P, Hagege AA. Long-term efficacy of myoblast transplantation on regional structure and function after myocardial infarction. Circulation. 2002 (Suppl 1); 106:I131-136.

19. Chachques JC, Duarte F, Cattadori B, Shafy A, Lila N, Chatellier G, Fabiani JN, Carpentier AF. Angiogenic growth factors and/or cellular therapy for myocardial regeneration: a comparative study. J Thorac Cardiovasc Surg. 2004; 128:245-253.

20. Menasche P, Hagege AA, Vilquin JT, Desnos M, Abergel E, Pouzet B, Bel A, Sarateanu S, Scorsin M, Schwartz K, Bruneval P, Benbunan M, Marolleau JP, et al. Autologous skeletal myoblast transplantation for severe postinfarction left ventricular dysfunction. J Am Coll Cardiol. 2003; 41:1078-1083.

21. Menasche P, Hagege AA, Scorsin M, Pouzet B, Desnos M, Duboc D, Schwartz K, Vilquin JT, Marolleau JP. Myoblast transplantation for heart failure. Lancet. 2001; 357:279280.

22. Herreros J, Prosper F, Perez A, Gavira JJ, GarciaVelloso MJ, Barba J, Sanchez PL, Canizo C, Rabago G, Marti-Climent JM, Hernandez M, Lopez-Holgado N, 
Gonzalez-Santos JM, et al. Autologous intramyocardial injection of cultured skeletal muscle-derived stem cells in patients with non-acute myocardial infarction. Eur Heart J. 2003; 24:2012-2020.

23. Menasche P, Alfieri O, Janssens S, McKenna W, Reichenspurner H, Trinquart L, Vilquin JT, Marolleau JP, Seymour B, Larghero J, Lake S, Chatellier G, Solomon S, et al. The Myoblast Autologous Grafting in Ischemic Cardiomyopathy (MAGIC) trial: first randomized placebocontrolled study of myoblast transplantation. Circulation. 2008; 117:1189-1200.

24. Tsung A, Tohme S, Billiar TR. High-mobility group box-1 in sterile inflammation. J Intern Med. 2014; 276:425-443.

25. Jin C, Cleveland JC, Ao L, Li J, Zeng Q, Fullerton DA, Meng X. Human myocardium releases heat shock protein 27 (HSP27) after global ischemia: the proinflammatory effect of extracellular HSP27 through toll-like receptor (TLR)-2 and TLR4. Mol Med. 2014; 20:280-289.

26. Frantz S, Nahrendorf M. Cardiac macrophages and their role in ischaemic heart disease. Cardiovasc Res. 2014; 102:240-248.

27. Ono K, Matsumori A, Shioi T, Furukawa Y, Sasayama S. Cytokine gene expression after myocardial infarction in rat hearts: possible implication in left ventricular remodeling. Circulation. 1998; 98:149-156.

28. Deswal A, Petersen NJ, Feldman AM, Young JB, White BG, Mann DL. Cytokines and cytokine receptors in advanced heart failure: an analysis of the cytokine database from the Vesnarinone trial (VEST). Circulation. 2001; 103:2055-2059.

29. Timmers L, Pasterkamp G, de Hoog VC, Arslan F, Appelman Y, de Kleijn DP. The innate immune response in reperfused myocardium. Cardiovasc Res. 2012; 94:276-283.

30. Timmers L, Sluijter JP, van Keulen JK, Hoefer IE, Nederhoff MG, Goumans MJ, Doevendans PA, van Echteld CJ, Joles JA, Quax PH, Piek JJ, Pasterkamp G, de Kleijn DP. Toll-like receptor 4 mediates maladaptive left ventricular remodeling and impairs cardiac function after myocardial infarction. Circ Res. 2008; 102:257-264.
31. Zhou M, Zhang Y, Chen X, Zhu J, Du M, Zhou L, Zhang L, Wang W, Sun G. PTEN-Foxo1 signaling triggers HMGB1mediated innate immune responses in acute lung injury. Immunol Res. 2015; 62:95-105.

32. Fan W, Morinaga H, Kim JJ, Bae E, Spann NJ, Heinz S, Glass CK, Olefsky JM. FoxO1 regulates Tlr4 inflammatory pathway signalling in macrophages. EMBO J. 2010; 29:4223-4236.

33. Knorr M, Munzel T, Wenzel P. Interplay of NK cells and monocytes in vascular inflammation and myocardial infarction. Front Physiol. 2014; 5:295.

34. Itabashi Y, Miyoshi S, Yuasa S, Fujita J, Shimizu T, Okano T, Fukuda K, Ogawa S. Analysis of the electrophysiological properties and arrhythmias in directly contacted skeletal and cardiac muscle cell sheets. Cardiovasc Res. 2005; 67:561-570.

35. Leobon B, Garcin I, Menasche P, Vilquin JT, Audinat E, Charpak S. Myoblasts transplanted into rat infarcted myocardium are functionally isolated from their host. Proc Natl Acad Sci U S A. 2003; 100:7808-7811.

36. Dib N, Michler RE, Pagani FD, Wright S, Kereiakes DJ, Lengerich R, Binkley P, Buchele D, Anand I, Swingen C, Di Carli MF, Thomas JD, Jaber WA, et al. Safety and feasibility of autologous myoblast transplantation in patients with ischemic cardiomyopathy: four-year follow-up. Circulation. 2005; 112:1748-1755.

37. Liu X, Cao H, Li J, Wang B, Zhang P, Dong Zhang X, Liu Z, Yuan H, Zhan Z. Autophagy induced by DAMPs facilitates the inflammation response in lungs undergoing ischemia-reperfusion injury through promoting TRAF6 ubiquitination. Cell Death Differ. 2017; 24:683-693. 